\title{
Bullying among nurses and its effect on their turnover intention at Menoufia University Hospitals
}

\author{
Esraa A. Moslam ${ }^{1}$, Manal M. Ibrahim ${ }^{2}$ and Gehan M. Diab ${ }^{3}$ \\ ${ }^{1}$ B.SC in nursing sciences, ${ }^{23}$ professorof Nursing Administration ,Faculty of Nursing, \\ Menoufia University
}

\begin{abstract}
Background: Workplace Bullying is becoming an important public health problem that is concerning physicians and health team members. Bullying has been advocated as an important factor that effect on nursing turnover at the workplace. Aim: The aim of this study was to assess the workplace bullying among nurses and its effect on their turnover intention. Design: A descriptive correlational research design was conducted at Menoufia University Hospitals at Shebin-ELkom. Sampling: A convenience sample of 295 nurses was included in this study. Results: Revealed that nurses had exposed to workplace bullying moderately and more than half of the studied nurses had intention to turnover. Conclusion: There was a positive highly statistical correlation between nurse's exposure to bullying and their turnover intention. Recommendation: Develop strategies and policies to develop the necessary vision to engage and retain talented nurses.
\end{abstract}

Key Words: Bullying and nursing turnover intention.

\section{Introduction:}

International Journal of Adolescent Medicine and Health , 2020 mentioned that the involvement of individuals in violent behaviors is becoming an important public health problem that is concerning physicians and health team members as it is associated with a decrease in adult life quality. In this context, bullying is a type of aggressive behavior that occurs repeatedly in interpersonal relationship where power imbalance exists increasing the risk of physical and psychosocial problems. Prevalence of bullying in health organizations is estimated to be ranging from 16.2 to 27.5\%, (Roberts,et al 2020).

Nurses worldwide have similar problems with bullying, which is known to have harmful effects on the victims' health, nursing profession, safety and quality of patient care, as well as on working environment in healthcare sectors, retention of nurses, turnover intention and employers' costs. Workplace bullying has been 


\section{Bullying among nurses and its effect on their turnover intention at Menoufia University Hospitals}

linked to negative health outcomes and mental health problems; bullied nurses are more likely to have headaches, hypertension, intestinal problems, fatigue, sleep disturbances, anxiety, irritability, depression, psychological distress and burnout, compared with non-bullied nurses (American Nurses Association,2017). Turnover intention is defined as the central mental prospector of their definite turnover action and the final stage before they display action of exit from the organization ( Tett and Mayer,2019).

Bullying results in increased turnover rate when nurses decided to leave the organization instead of remaining in a workplace where they are unhappy (Larson, 2018). Sometimes, the organization is unaware of what is going on and showed the individual being bullied as the problem, causing him or her to feel even more isolated and increasing the likelihood of leaving the organization (Cleary et al., 2019).

The consequences of workplace bullying can be strongly. Notably, it is a major reason why nurses leave their profession, some reactions in response to bullying include anger, weight loss/gain, low self-esteem, altered sleep patterns, alcoholism and complex social and work relationships among team members.( Ahliquist and Riehl ,2018).

\section{Significance of the Study:}

Recently, the phenomena of Bullying is considered big problem especially in healthcare organization and the importance of studying workplace bullying has been underscored by findings that show workplace bullying among nurses can lead to increase level of nurses turnover. Nurses that exposed to violence can report low degree of job satisfaction, burnout and high desire to leave the organization. From the investigator clinical experience it was noticed those nurses always express negative feelings, encounter verbal and nonverbal abuse and the desire to leave the work. So this study will investigate the effect of bullying on nurses turnover intention.

\section{Purpose of the Study:}

To explore the workplace bullying among nurses and its effect on their turnover intention through the following objectives:

- Determine workplace bullying among nurses at Menofia 


\section{Bullying among nurses and its effect on their turnover intention at Menoufia \\ University Hospitals}

University Hospitals.

- Assess the nurses turnover intention at Menoufia University Hospitals.

- Determine the most common causes of nurses' turnover at Menoufia university hospitals.

- Explore the relationship between workplace bullying among nurses and their turnover intention at Menoufia University Hospitals.

\section{Research Hypothesis:}

There are positive relationship between workplace bullying and turnover intention among nurses.

\section{Research design:}

A descriptive correlational design was used to carry out this study.

\section{Setting:}

The study was conducted in general departments and closed units at selected Menoufia University hospitals. Menoufia University hospitals is one of the largest hospitals in Delta region. This hospital constitutes four buildings (General hospital, Emergency hospital, specialized hospital, and Oncology hospital). The bed capacity of the hospital is 700 beds .The estimated number of nursing workforce in the hospital is 1280 with different educational levels in nursing. This study was conducted at following units: Intensive care unit ,emergency department, operation rooms, oncology hospital, surgical department ,medical department and dialysis department

\section{Sample:}

General frame will be constructed for all nurses working. Using a convenient sample was chosen at selected Menoufia University hospitals.

Inclusion criteria: The nurses must

- Have at least one years of experience

- *Accept to participate in the study

- Being exposed to bullying at least 6 months before participating in the study.

\section{Sample Size:}

Health care is at Menoufia University hospitals provided by 1280 nurses are distributed into 800 nurses in critical care units 400 in medical departments (statistical Administrative Records of Hospitals, 2018). The total number of nurses to be selected was estimated using the following equation:

$$
\mathrm{SS}=\frac{Z^{2 *}(p) *(1-p)}{C^{2}}
$$

where

$\mathbf{Z}=\mathbf{Z}$ value (e.g 1.96 for $95 \%$ confidence level) 


\section{Bullying among nurses and its effect on their turnover intention at Menoufia University Hospitals}

$\mathrm{P}=$ percentage picking a choice, expressed as decimal (5 used for sample size needed)

$\mathrm{C}=$ confidence interval expressed as decimal (e.g .04 =+_ 4)

Based on past review of literature that reported the correlation between bullying and nursing turnover level to be 0.16 (Bas, Ogul and Ozgür, 2016), sample size had been calculated at $80 \%$ power and CI $95 \%$ and it was be 295 nurses.

\section{Instruments for data collection:}

Two instruments were used to conduct this study:

\section{1-The first instrument consist of two} parts

- The first Part: Consisted of the nurses demographic information, such as age, education, experience ...,etal.

- The second part: Negative Acts Questionnaire-Revised (NAQR) was developed by (Einarsen and Hoel, 2001). This instrument measures work place bullying by asking nurses to rate how frequently they have been exposed to negative acts at their workplace in the last six months before participating in the study. It consists of 22 items that were classified into three domains: work related bullying (seven items), person related bullying (twelve items), and physically intimidating bullying (three items).

-Scoring system: NAQ-R is a fivepoint likert scale, ranging from never to daily (1-5); never ( 1 ), now and then ( 2 ), monthly ( 3 ), weekly ( 4 ), and daily ( 5 ). The overall NAQ-R score is 110, ranges from 22 (respondent never experienced any of the 22 negative behaviors) to maximum of 110 (respondent experienced all of the 22 negative behaviors on a daily basis). For each domain, the scores of the items were summed-up and the total was divided by the number of the items, giving a mean score for each part if score be > 66 that are considered exposure to bullying. The scoring system for bullying instrument was $<60 \%$ Mild $(<66), \quad(60-75) \%$ Moderate (6683 )and $>75 \%$ Severe $(>83)$.

\section{2-The second instrument: Nursing} turnover Intention: consist of two parts:

-1-The first part: Nurses turnover intention, measured by this instrument adopted by Boshoff and Allen's, (2000) three-item scale. The 


\section{Bullying among nurses and its effect on their turnover intention at Menoufia University Hospitals}

items were: (1) I think a lot about leaving the organization, (2) I am actively searching for an alternative to the organization, and (3) As soon as it is possible, I will leave the organization.

Each statement in the Boshoff and Allen, (2000) instrument uses a five point Likert-type scale in which, $1=$ strongly disagree, $2=$ agree, $3=$ neither agree nor disagree, $4=$ agree, and 5 = strongly agree". Minimum score is 3 and the maximum score is 15. Higher score indicated higher intention to leave a job. The midpoint score is 9 .

Scoring system: Each statement in the Boshoff and Allen ,(2000)instrument uses a five point Likert-type scale in which, $1=$ strongly disagree, $2=$ agree, $3=$ neither agree nor disagree, $4=$ agree, and 5 = strongly agree". Minimum score is 3 and the maximum score is 15. Higher score indicated higher intention to leave a job. The midpoint score is 9. Intent of nurses to be retained in work with score $<60 \%$ $(<9)$, Intent of nurses to turnover from work with score $\geq 60 \%(\geq 9)$.

2-The second part : contributing factors of turnover was adopted by Ali, (1998) that consist of 14 contributing factors of turnover which include : Living far away from hospital, unavailability of transportation from and to hospital, heavy work load, work on bad working relation with nursing supervisors ,there is better chance at anther workplace, instability at work, unsatisfactory salary, no promotional opportunity, patients and relatives relations ,scheduling system, family responsibility ,no continuous education opportunity, no postgraduate studies, no precautions for the safety and security of the work .

Scoring system :The subjects give items $\operatorname{rank}(1-5)$ considered as agree substantially which assigned a score of "three", the subject give items rank (6-8) considered as agree moderately which assigned a score of "two" \& the subjects give items rank (9-14)considered as agree weekly which assigned a score of one.

\section{Procedure:}

The purpose, nature, the potential benefits and time of conducting this study were explained to each staff nurse and their agreement was assured to participate in the study. The two instruments were translated to Arabic, 


\section{Bullying among nurses and its effect on their turnover intention at Menoufia University Hospitals}

the validity and reliability was done .Data was collected from staff nurses and their patients from the prementioned study setting. Data was collected using the self-administered questionnaires; which were filled by the nurses themselves during working hours and filling them needed from 10:15 minutes. Data collection lasted for 3 months, from January 2020 to March 2020.

\section{Ethical consideration:}

Before starting the study, the researcher was met with the director of the hospital to explain the aim of the study and get their permission to carry out the study. This helped by official letters from the dean of the faculty of nursing at menoufia University was sent to the director of the menoufia university hospitals. The study was conducted with careful attention to ethical standards of research and rights of the participants. The respondent's rights were protected by ensuring voluntary participation; so that an informed consent was obtained by explaining the purpose, nature, the potential benefits and time of conducting this study, how data was collected, any needed procedures, expected outcomes and their right to withdraw from the research study at any time in case of violation of their rights.

\section{Validity of the study instruments:}

The study instruments were tested for validity (face \& content) through distribution of them to a panel of experts consisted of 3 assistant professors in the field of nursing administration and 2 assistant professors from psychiatric nursing department to judge the content and face validity of the instruments, presented from nursing Menoufia university. The needed modifications were done by the investigator. The period taken by the experts group lasted from october2019 to december2019.

\section{Reliability of the study instruments:}

- Cronbach's Alpha for first instrument is 0.912 for 22 items applied on 30 nurses.

- Cronbach's Alpha for second instrument is 0.873 for 17 items applied on 30 nurses.

- Cronbach's Alpha for the sheet in total is 0.894 for 39 items applied on 30 nurses.

- Statistical design:

The collected data were organized, tabulated and statistically analyzed 


\section{Bullying among nurses and its effect on their turnover intention at Menoufia University Hospitals}

using SPSS software statistical computer package version 25 and the study sample was calculated using the Epi-info program. For quantitative data, the range, mean and standard deviation were calculated. For qualitative data, comparison was done using Chi-square test $\left(\chi^{2}\right)$. Correlation between variables was evaluated using
Pearson and Spearman's correlation coefficient $r$ and Fisher Exact test. A significance was adopted at $\mathrm{P}<0.05$ for interpretation of results of tests of significance (*). Also, a highly significance was adopted at $\mathrm{P}<0.01$ for interpretation of results of tests of significance (**) (Gerstman, 2008).

\section{Result:}

Table (1): Percent distribution of the studied nurses according to their socio-demographic characteristics.

\begin{tabular}{|l|c|c|}
\hline \multirow{2}{*}{ Characteristics } & \multicolumn{2}{|c|}{$\begin{array}{c}\text { The studied nurses } \\
\text { (n=295) }\end{array}$} \\
\cline { 2 - 3 } Age (in years) & N & \% \\
\hline - (<25) & 118 & 40.0 \\
- (25-<35) $(35-<45)$ & 137 & 46.4 \\
- ( $\geq 45)$ & 38 & 12.9 \\
\hline Educational level & 2 & 0.7 \\
\hline - Nursing Diploma & & \\
- Technical nursing Institute & 60 & 20.3 \\
- Nursing Bachelor & 110 & 37.3 \\
\hline Experience (in years) & 125 & 42.4 \\
\hline - (<5) & & \\
- (5-<15) & 114 & 38.6 \\
- (15-<25) & 142 & 48.1 \\
- (25-30) & 34 & 11.5 \\
\hline Marital status & 5 & 1.7 \\
\hline - Married & & \\
- Not married & 198 & 67.1 \\
\hline Work unitlDepartment & 97 & 32.9 \\
\hline - Emergency department & & \\
- Surgical. Department & 29 & 9.8 \\
- Medical. Department & 38 & 12.9 \\
- Intensive Care Unit & 40 & 13.6 \\
- Operation .Rooms & 38 & 12.9 \\
- Dialysis .Department & 60 & 20.3 \\
- Neonatal ICU & 26 & 8.8 \\
- Oncology .Hospital & 34 & 11.5 \\
\hline Have you been subjected to acts of & & 10.2 \\
bullying? & 30 & \\
- Yes & & 79.0 \\
- No & 62 & 21.0 \\
\hline & & \\
\hline
\end{tabular}




\section{Bullying among nurses and its effect on their turnover intention at Menoufia University Hospitals}

Table (1): it illustrated distribution of nurses according to their sociodemographic characteristics. This table shows that the highest percent $(46.4 \%)$ of nurses were in age group (25 to-< 35).Regarding educational level, the highest percent (42.4\%) were holding nursing bachelor. According to nurses experience almost of the nurses $(48.1 \%)$ observed in $(15-<25)$ group of experience years. had less than fifteen years. In addition the most of the study sample nurses $(20.3 \%)$ were working at operating room. Furthermore, in relation to marital status and being a subject to bullying acts, the majority (67.1\%) of the studied nurses were married and subjected to acts of bullying with percent (79\%).

Table (2): Percentage distribution of the studied nurses according to their total level of exposure to workplace bullying:

\begin{tabular}{|l|c|c|c|c|c|c|}
\hline \multirow{2}{*}{$\begin{array}{l}\text { Workplace bullying } \\
\text { Dimensions levels }\end{array}$} & \multicolumn{4}{|c|}{ The studied nurses (n=295) } \\
\cline { 2 - 8 } & \multicolumn{2}{|c|}{ Mild } & \multicolumn{2}{|c|}{ Moderate } & \multicolumn{2}{c|}{ Severe } \\
\cline { 2 - 7 } & $\mathbf{N}$ & $\mathbf{\%}$ & $\mathbf{N}$ & $\mathbf{\%}$ & $\mathbf{N}$ & $\mathbf{\%}$ \\
\hline 1. Work related bullying & 166 & 56.3 & 107 & 36.3 & 22 & 7.5 \\
\hline 2. Person related bullying & 95 & 32.2 & 178 & 60.3 & 22 & 7.5 \\
\hline 3. Physically intimidating bullying & 202 & 68.5 & 61 & 20.7 & 32 & 10.8 \\
\hline Total workplace bullying level & $\mathbf{8 9}$ & $\mathbf{3 0 . 2}$ & $\mathbf{1 7 9}$ & $\mathbf{6 0 . 7}$ & $\mathbf{2 7}$ & $\mathbf{9 . 1}$ \\
\hline
\end{tabular}

$<60 \%$ Mild

(60-75) \% Moderate

$>75 \%$ Severe

Table (2): it clarified the percent distribution of the studied nurses according to their level of exposure to workplace bullying. It showed that the highest level at work related bullying dimension were mild with a percentage $(56.3 \%)$ and the lowest level were at severe with a percentage $(7.5 \%)$, the highest level at person related bullying dimension were moderate with a percentage $(60.3 \%)$ and the lowest level were at severe with a percentage $(7.5 \%)$ and the highest level at physically intimidating bullying were mild with a percentage $(68.5 \%)$ while the lowest level were at sever with a percentage $(10.8 \%)$.

Figure (1): Total Percent distribution of the studied nurses level of exposure to workplace bullying 


\section{Bullying among nurses and its effect on their turnover intention at Menoufia \\ University Hospitals}

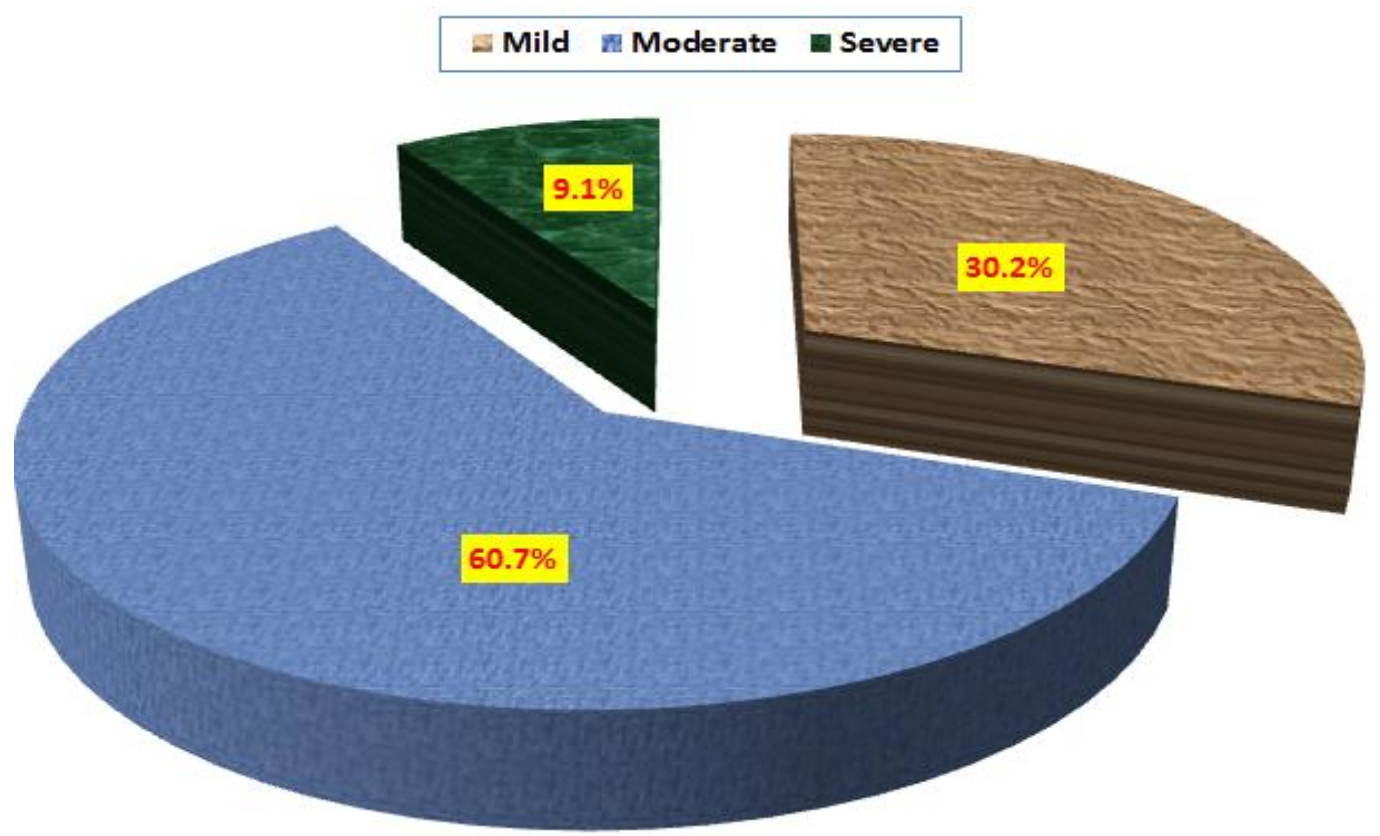

Figure (1): it illustrated the percent exposed to workplace bullying distribution of the studied nurses according to their level of exposure to workplace bullying. It showed that the moderately and the minimum of the studied nurses were exposed to workplace bullying severely.

Table (3): Percentage distribution of the studied nurses according to their level of nursing turnover intention.

\begin{tabular}{|l|c|c|}
\hline \multirow{2}{*}{ Level of nursing turnover intention } & \multicolumn{2}{|c|}{$\begin{array}{c}\text { The studied nurses } \\
\text { (n=295) }\end{array}$} \\
\cline { 2 - 3 } & $\mathbf{N}$ & \% \\
\hline - Intent to be retained & 84 & 71.5 \\
\hline Range & 211 & $\mathbf{( 3 - 1 5 )}$ \\
Mean \pm SD & \multicolumn{2}{|c|}{$\mathbf{1 0 . 1 1 \pm 3 . 0 9 6}$} \\
\hline
\end{tabular}

$<60 \%(<9)$ Intent to be retained

$\geq 60 \%(\geq 9)$ Intent to turnover

Table (3): It showed the percentage distribution of the studied nurses according to their level of nursing turnover intention. It clarified that the highest percentage of the studied nurses was intended to turnover with percentage $71.5 \%$ while the low percent of the studied nurses was intended to retain with percentage $28.5 \%$. 


\section{Bullying among nurses and its effect on their turnover intention at Menoufia University Hospitals}

Table (4): Percentage distribution and Ranking of the studied nurses according to their contributing factors of turnover.

\begin{tabular}{|c|c|c|c|c|}
\hline Contributing factors of turnover & $\begin{array}{c}\text { Agree } \\
\text { weakly }\end{array}$ & $\begin{array}{c}\text { Agree } \\
\text { moderately }\end{array}$ & $\begin{array}{c}\text { Agree } \\
\text { substantially }\end{array}$ & Rank \\
\hline $\begin{array}{c}\text { Living far away from hospital } \\
\mathrm{N} \\
\%\end{array}$ & $\begin{array}{l}132 \\
44.7\end{array}$ & $\begin{array}{c}58 \\
19.7\end{array}$ & $\begin{array}{l}105 \\
35.6\end{array}$ & 9 \\
\hline $\begin{array}{l}\text { Unavailability of transportation from and to } \\
\text { hospital } \\
\qquad \begin{array}{l}\mathrm{N} \\
\%\end{array}\end{array}$ & $\begin{array}{l}124 \\
42.0\end{array}$ & $\begin{array}{c}79 \\
26.8\end{array}$ & $\begin{array}{c}92 \\
31.2\end{array}$ & 11 \\
\hline $\begin{array}{l}\text { Heavy work load } \\
\mathrm{N} \\
\%\end{array}$ & $\begin{array}{c}83 \\
28.1\end{array}$ & $\begin{array}{c}86 \\
29.2\end{array}$ & $\begin{array}{r}126 \\
42.1\end{array}$ & 4 \\
\hline $\begin{array}{l}\text { Work on dad relation with nursing supervisors } \\
\mathrm{N} \\
\%\end{array}$ & $\begin{array}{c}70 \\
23.7\end{array}$ & $\begin{array}{c}98 \\
33.2 \\
\end{array}$ & $\begin{array}{l}127 \\
43.1\end{array}$ & 3 \\
\hline $\begin{array}{l}\text { There is a better chance at anther workplace } \\
\mathrm{N} \\
\%\end{array}$ & $\begin{array}{c}84 \\
28.5 \\
\end{array}$ & $\begin{array}{r}103 \\
34.9 \\
\end{array}$ & $\begin{array}{c}108 \\
36.6 \\
\end{array}$ & 8 \\
\hline $\begin{array}{c}\text { Instability at work } \\
\text { N } \\
\%\end{array}$ & $\begin{array}{c}51 \\
17.3\end{array}$ & $\begin{array}{c}132 \\
44.7\end{array}$ & $\begin{array}{c}112 \\
38.0\end{array}$ & 7 \\
\hline $\begin{array}{l}\text { Unsatisfactory salary } \\
\mathrm{N} \\
\%\end{array}$ & $\begin{array}{c}48 \\
16.3 \\
\end{array}$ & $\begin{array}{c}99 \\
33.6\end{array}$ & $\begin{array}{r}148 \\
50.2\end{array}$ & 1 \\
\hline $\begin{array}{c}\text { No promotional opportunity } \\
\mathrm{N} \\
\% \\
\end{array}$ & $\begin{array}{c}53 \\
18.0\end{array}$ & $\begin{array}{r}140 \\
47.5 \\
\end{array}$ & $\begin{array}{c}102 \\
34.6\end{array}$ & 10 \\
\hline $\begin{array}{c}\text { Patients and relatives relations } \\
\mathrm{N} \\
\% \\
\end{array}$ & $\begin{array}{c}56 \\
19.0 \\
\end{array}$ & $\begin{array}{r}119 \\
40.3 \\
\end{array}$ & $\begin{array}{l}120 \\
40.7 \\
\end{array}$ & 5 \\
\hline $\begin{array}{c}\text { Scheduling system } \\
\mathrm{N} \\
\%\end{array}$ & $\begin{array}{l}43 \\
14\end{array}$ & $\begin{array}{l}125 \\
42.4\end{array}$ & $\begin{array}{l}127 \\
43.6\end{array}$ & 2 \\
\hline $\begin{array}{l}\text { Family responsibility } \\
\mathrm{N} \\
\% \\
\end{array}$ & $\begin{array}{c}59 \\
20.0\end{array}$ & $\begin{array}{r}119 \\
40.3 \\
\end{array}$ & $\begin{array}{r}117 \\
39.7 \\
\end{array}$ & 6 \\
\hline $\begin{array}{l}\text { No continuous education opportunity } \\
\mathrm{N} \\
\%\end{array}$ & $\begin{array}{c}102 \\
34.6\end{array}$ & $\begin{array}{r}109 \\
36.9\end{array}$ & $\begin{array}{c}84 \\
28.5\end{array}$ & 12 \\
\hline $\begin{array}{l}\text { No postgraduate studies } \\
\mathrm{N} \\
\%\end{array}$ & $\begin{array}{l}125 \\
42.4\end{array}$ & $\begin{array}{r}106 \\
35.9\end{array}$ & $\begin{array}{c}64 \\
21.7\end{array}$ & 13 \\
\hline $\begin{array}{l}\text { No precautions for safety and security of the work } \\
\text { N } \\
\%\end{array}$ & $\begin{array}{l}138 \\
46.8\end{array}$ & $\begin{array}{c}98 \\
33.2\end{array}$ & $\begin{array}{c}59 \\
20.0\end{array}$ & 14 \\
\hline
\end{tabular}

Table (4): it illustrated percentage percentage $50.2 \%$ agree substantially distribution and ranking of the studied nurses according to their contributing factors of turnover. It clarified the highest ranked contributing factor of ,while the lowest ranked contributing factor of turnover was no precautions for safety and security of the work with a percentage $46.8 \%$ agree weakly. turnover was unsatisfactory salary with 
Bullying among nurses and its effect on their turnover intention at Menoufia University Hospitals

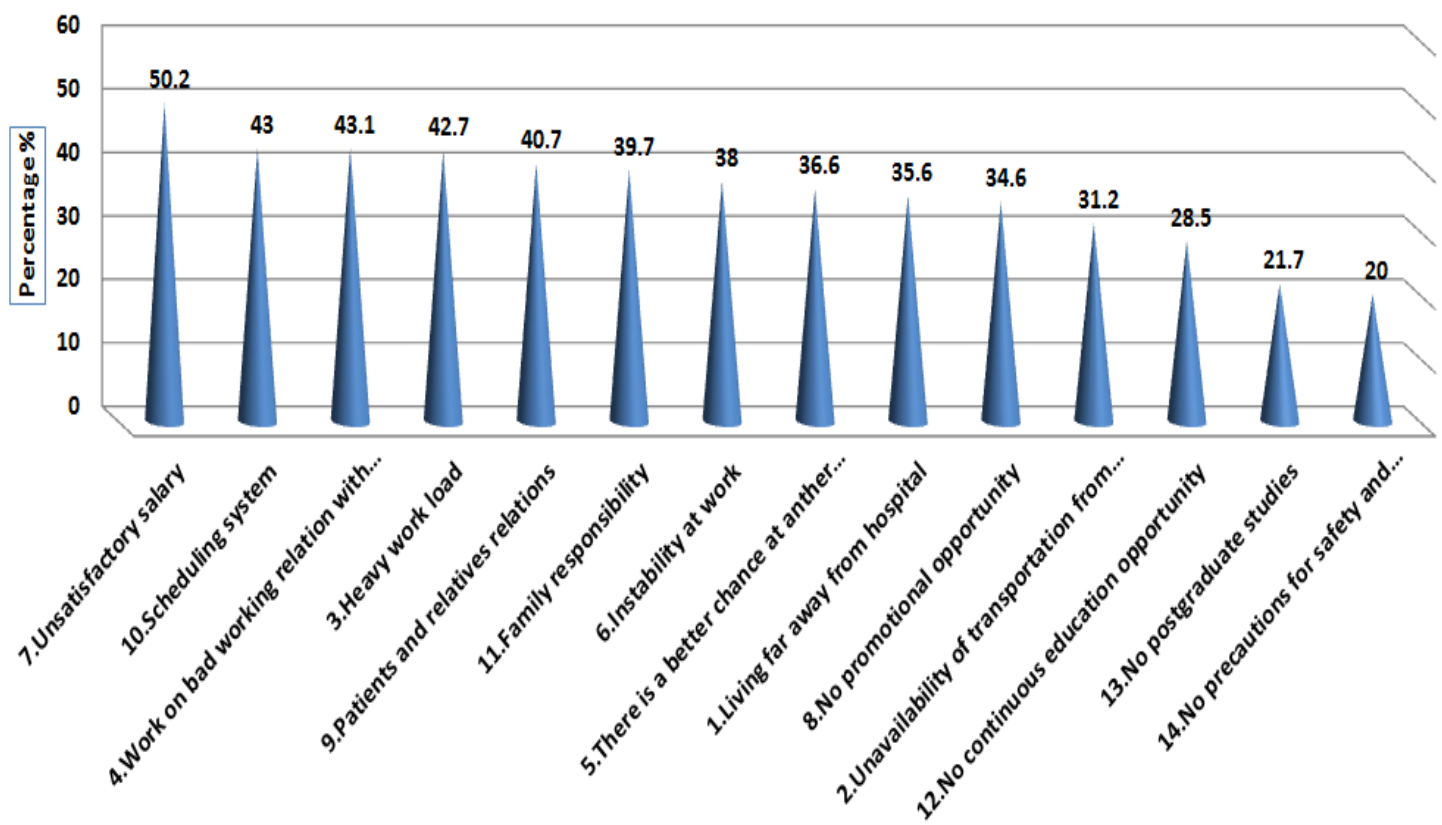

Figure (2): it illustrated percentage distribution of the studied nurses according to their contributing factors of turnover. It showed that the highest three factor of turnover were unsatisfactory salary $(50.2 \%)$ followed by scheduling system (48\%) and then work on bad relations $(43 \%)$ while the lowest factor of turnover was no precautions for safety and security ( 20 $\%)$.

Table (5): Correlation between workplace bullying dimensions of the studied nurses and total nursing turnover intention score:

\begin{tabular}{|c|c|c|}
\hline \multirow{2}{*}{ Workplace bullying dimensions } & \multicolumn{2}{|c|}{$\begin{array}{c}\text { The studied nurses } \\
(\mathbf{n = 2 9 5})\end{array}$} \\
\cline { 2 - 3 } & \multicolumn{2}{|c|}{$\begin{array}{c}\text { Total nursing turnover } \\
\text { intention score }\end{array}$} \\
\cline { 2 - 3 } & \multicolumn{2}{|c|}{$\mathbf{P}$} \\
\cline { 2 - 3 } 1. Work related bullying & $\mathbf{R}$ & $\mathbf{0 . 0 0 0} * *$ \\
3. Person related bullying & $\mathbf{0 . 5 0 3}$ & $\mathbf{0 . 0 0 0} * *$ \\
\hline Total bullying score & $\mathbf{0 . 4 6 8}$ & $\mathbf{0 . 0 0 0} * *$ \\
\hline
\end{tabular}

r: Pearson' correlation coefficient

* Significant at level $\mathrm{P}<0.05$.

$* *$ Highly significant at level $\mathrm{P}<0.01$.

Table (5): it clarified the correlation between workplace bullying dimensions of the studied nurses and total nursing turnover intention score .It showed that there was highly statically significant correlation between workplace bullying dimensions and nursing turnover intention scores. 


\section{Bullying among nurses and its effect on their turnover intention at Menoufia University Hospitals}

\section{Discussion:}

The health care organization has been identified as one of workplace bullying can occurs frequently. Bullying present in all work environments but nurses are on the frontline of the health care system and have the closest contact with patients and their relatives. Bullying is a serious issue affecting the nursing profession. It has serious negative consequences that may extend beyond individual nurses to an entire health care organization such as experiencing stress, frustration, physical and psychological disorders, absenteeism, poor performance and leave a particular place of employment (Samir et al., 2012; Yamada et al., 2018).

Turnover intention is one's voluntary intention to cease from being employed by the current employer. It is a conscious willfulness to leave the organization from the nurse's own wills to evaluate other opportunities. It is thought of turnover intentions that lead to an actual turnover. Turnover intention has critical importance to organizations because it influences stability and productivity and it proves to be very costly (Nawaz et al., 2015; El-Sakka, 2016; Osman et al., 2016; Klerk and Stander, 2014).
The present study aimed to assess workplace bullying among nurses and its effect on their turnover intention through the following objectives: determine workplace bullying among nurses at Menoufia University Hospitals, assess the nurses` turnover intention at Menoufia University Hospitals ,determine causes of nurses turnover at Menoufia University Hospitalsand explore the relationship between workplace bullying among nurses and their turnover intention at Menoufia University Hospital.

\section{Part I: Personal characteristics of}

\section{studied nurses.}

The findings of the present study showed that the highest percent of nurses in the study sample were at age ranges from 25 to less than 35 years and the percentage was 46.4 . According to nurses experience range from 5to less than 15 years of experience with percentage48.1. In addition, the most of the study sample nurses were working at operating room. Regarding educational level, the majority of the study sample nurses had associated bachelor in nursing. Furthermore, in relation to marital status and being a subject to 


\section{Bullying among nurses and its effect on their turnover intention at Menoufia University Hospitals}

bullying acts, the majority of the studied nurses were married and subjected to acts of bullying. .From the investigator point of view, most of young nurses have either associated degree or bachelor degree in nursing especially after diploma in nursing has been cancelled .Moreover, nurses with bachelor degree were usually distributed in critical care units while nurses with associated degree were distributed in departments.

Part II: Exposure to workplace bullying about work related bullying domain.

According to the results of the present study clarified the percent distribution of the studied nurses according to their level of workplace bullying. It showed that the majority of the studied nurses were exposed to workplace bullying moderately. Also, illustrated the percent distribution of the studied nurses according to their level of workplace bullying. It showed that the maximum of the studied nurses were exposed to workplace bullying moderately and the minimum of the studied nurses were exposed to workplace bullying severely.

This results was supported by Mohammed, (2019) who conducted study about "effect of work place bullying on nurses' job performance" and reported that the nearly three quarter of staff nurses had moderate level of bullying. Also, The result of the present study agreed with Nwaneri et al. (2016) found workplace bullying among nurses is reported to be high.

In the opposite line, Simons, (2018) who conducted study about "Workplace bullying experienced by Massachusetts registered nurses and the relationship to intention to leave the organization." and reported that majority of participants reported that they have never been bullied. By far, most respondents reported to be bullied sometimes or more rarely. Also, disagreed with Katrinli et al., (2019) they studied "Nurses' perceptions of individual and organizational political reasons for horizontal peer bullying" and found high percent of respondents stated they were bullied at work only rarely and minority of the said on a daily basis.

Part III: the nurses turnover intention at Menoufia University

\section{Hospitals.}

Concerning level of nursing turnover intention. The results of the 


\section{Bullying among nurses and its effect on their turnover intention at Menoufia University Hospitals}

present study clarified that the majority of the studied nurses was intended to turnover and the minority of the studied nurses was intended to retain .

From the investigator point of view, this might be due to staff nurses want to modify their job and some of them want to move from public hospital to private hospital because of low salary. When nurses exposed to workplace bullying either from doctors or peers and from patients, they might thinking about leave the hospital. Also nurses' perceptions of whether their efforts were being rewarded by their organizations influence their decisions to stay at their organizations.

The result of the present study contrasted with Mohammed, (2020) who conducted study about 'Nurses' organizational trust perception and it's relation with intention to stay working at Benha University Hospital" and found that more than half of staff nurses had a moderate level of intention to stay at work.

In the same line the result of the present study agreed with Satoh et al., (2017) who conducted study about" Occupational commitment and job satisfaction mediate effort-reward imbalance and the intention to continue nursing "they reported that the majority of nurses had moderate level of intention to continue nursing and stay at work.

Also the result of the present study agreed with Liangh et al., (2016) who conducted study about" Nurse characteristics, leadership, safety climate, emotional labor and intention to stay for nurses: a structural equation modeling approach " they reported that most of nurses had moderate level of intention to stay at work.

At the opposite line the result of the present study unsupported by Honda\& Takamizawa ,(2017) who conducted study about" Factors influencing intention to continue employment in Japanese hospital nurses working at tertiary emergency medical facilities" they reported that most of nurses had low level of intention to stay at work.

The result of the present study was disagreement with Shacklock \& Brunetto, (2016) who conducted study about" The intention to continue nursing: work variables affecting three nurse generations in Australia" they reported that most of nurses had high level of intention to stay at work. 


\section{Bullying among nurses and its effect on their turnover intention at Menoufia University Hospitals}

According to the contributing factors of turnover. The results of the present study illustrated the highest contributing factors of turnover were unsatisfactory salary ,scheduling system and work in bad relations with supervisors agree substantially, while the lowest contributing factors of turnover was no precautions for safety and security of the work, no postgraduate studies and no continuous education opportunity with agree weakly. From the researcher point of view this result may be due to low salary, unavailable job security domains in the work, nurses responsibilities' of their families and may be due to the weak role of leaders and managers of nursing in reinforcing nursing staff for the importance of determining their works in the best timeframe.

This result was in agreement with Elsherbeny \& El-Masry, (2018) who conducted study about" Job satisfaction among nurses working in Mansoura University Hospital : Effect of socio-demographic and work characteristic " they reported that the majority of nurses expressed low salary satisfaction. In the same line the result of the present study agreed with Basit \&Duygulu, (2017) who conducted study about" Nurses' organizational trust and intention to continue working at hospitals in Turkey" they reported that more than half of nurses are satisfied with working in this institution.

Moreover, this result was consistent with Lăzăroiu (2016) who conducted a study entitled "work motivation and organizational

behavior. Contemporary Readings in Law and Social Justice" found that more than half of the participants reported their desire for providing comfortable furniture and maintaining their safety at work.

On the other hand this result contrasted with Mohammed, (2020) that more than half of nurses had agreement with" satisfied with working in this institution ".this may be due to adapt of nurses with job circumstances. Also good relation and cooperation between nurses make them more satisfied.

This results disagree with Edoho et al. (2015) who conducted study about" Job satisfaction among nurses in public hospitals in Calabar " they reported that The majority of nurses expressed moderate job satisfaction in their work salary 


\section{Bullying among nurses and its effect on their turnover intention at Menoufia University Hospitals}

Part IV: the relationship between

workplace bullying among nurses

and their turnover intention at

\section{Menoufia University Hospital.}

The results of the present study showed that there was highly significant positive correlation between total workplace bullying level and nursing turnover intention level and clarified that there is highly significant correlation between workplace bullying dimensions and nursing turnover intention scores at the studied nurses.

This results came in harmony with Simons, (2018) who found that $31 \%$ of respondents reported being bullied and that bullying is a significant determinant in predicting intent to leave the organization $(\mathrm{B}=3.1, \mathrm{P}<$ .0005). Also, Stagg\& Sheridan, (2019) the conducted study about "Effectiveness of bullying and violence prevention programs" and reported that highly significance relation between exposure to workplace bullying and intention to stay working. In the same line, Yildirim, (2019) who conducted study about "Bullying among nurses and its effects" and reported that there was highly significant correlation between work place bullying and nursing level of intention to continue nursing and stay at work.

On the other hand the result of the present study was disagreement with Shacklock \& Brunetto, (2016) who conducted study about" The intention to continue nursing: work variables affecting three nurse generations in Australia" they reported that most no relation between work bullying and intention to stay at work

\section{Conclusion}

In the light of the present study results, it can concluded that more than half of nurses exposed to work place bullying and the majority of the nurses were intended to leave their work. Also, there were three main contributing factors of nurses' turnover that were unsatisfactory salary, scheduling system and work in bad relations with supervisors. Additionally, there is a highly significant positive correlation between workplace bullying among nurses and their intention to turnover

\section{Recommendation}

Based on the findings of the present study, the following recommendations are proposed as:

\section{At the practice level:}

* Nurse Managers should provide staff nurses with clear essential information regarding to workplace 


\section{Bullying among nurses and its effect on their turnover intention at Menoufia University Hospitals}

bullying behaviors, how and to whom they report these behaviors and strategies to reduce workplace bullying behaviors through distributing guiding brochures and posters at all organizational departments.

Nurse Managers should have clear understanding of hospital bullying policies and realize its importance to patients, staff nurses and to be able to plan and reduce workplace bullying.

Formulate a committee that is responsible for responding to and dealing with workplace bullying behaviors.

* Improve the compensation system of basic salary, incentives and bounses

Nurse Managers should be role model and encourage the health care team members (doctors-staff nurses-paramedical) to work together toward organizational goals rather than personal goals.

Encourage nurse managers and staff nurses' effective open communication links, participation in committees, ongoing meetings.
* Encourage nurses to report bullying behaviors without fear from punishment and know them how to do that.

* Nurse Managers should maintain availability of resources required to help staff nurses performing their job effectively such as equipment and supplies necessary for providing quality of patient care to increase job satisfaction of staff nurses.

\section{At the educational level:}

$\begin{array}{lcr}\text { Hospital administration, in } \\ \text { collaboration } & \text { with } & \text { staff } \\ \text { development } & \text { department should }\end{array}$ provide continuing education programs to update and reinforce nurse managers about workplace bullying behaviors, effects, dimensions and strategies to reduce and reinforce staff nurses information and skills about high self-esteem and improving job satisfaction.

Suggest to the dean of the faculty of nursing to engage workplace bullying topics in the educational curriculum at faculty of nursing to improve nursing students awareness level regarding it . 


\section{Bullying among nurses and its effect on their turnover intention at Menoufia University Hospitals}

\section{At the research level:}

Replication of the study on large sample size and different settings.

Further research is needed to staff nurses to assess the effect of workplace bullying among nurses on quality of patient care.

Further research is needed to assess how to reduce nursing turnover and improve nursing retention.

\section{Reference}

Ali, M.(1998). Rate and causes of turnover among nurses in selected hospitals in Cairo. Unpublished Master thesis in nursing college Cairo University.

Ahlquist E, Riehl G. (2019):Managing Lateral Violence and its impact on the team: Nurses and Students. Regina: Presented at the Inspire Health Care Quality Summit.

American Nurses Association [Internet]. Silver Spring: ANA Enterprise; 2017 [cited 2017 Sep 3]. Incivility, bullying, and workplace violence.

Cleary, M. et al . (2019). Identifying and addressing bullying in nursing. Issues in Mental Health Nursing; 31: 331-335.

Einarsen, S., \& Hoel, H., (2001). The negative acts questionnaire: development, validation, and revision of a measure of bullying at work. Einarsen, S., Hoel H., \& Notelaers, G. (2019). Measuring exposure to bullying and harassment at work: Validity, factor structure and psychometric properties of the Negative Acts Questionnaire-Revised. Work \& Stress: An International Journal of Work, Health \& Organizations, 23(1), 24-44.

Einarsen, S., \& Skogstad, A. (2016). Bullying at work: Epidemiological findings in public and private organizations. European Journal of Work and Organizational Psychology, 15(2), 185-201

Felblinger, D. M. (2018). Incivility and bullying in the workplace and nurses shame responses. Journal of Obstetrics, Gynecology, \& Neonatal Nursing, 37(2), 234-242.

Larson, J. (2018): Nurse bullying: An ongoing problem in the health care workplace.

Roberts, SJ. (2020): Lateral violence in nursing: a review of the past three decades. Nursing Science Quarterly.

Simons, S. (2018): Workplace bullying experienced by Massachusetts registered nurses and the relationship to intention to leave the organization. Advances in Nursing Science, 31(2), 48-59.

Stagg, S. J., \& Sheridan, D. (2019): Effectiveness of bullying and violence prevention programs: a systemic review. AAOHN Journal, 58(10). 